\title{
Paradoxical Neurobehavioral Rescue by Memories of Early-Life Abuse: The Safety Signal Value of Odors Learned during Abusive Attachment
}

\author{
Charlis Raineki*, 1,2,3, Emma Sarro',2, Millie Rincón-Cortés ${ }^{1,2}$, Rosemarie Perry ${ }^{1,2}$, Joy Boggs ${ }^{3}$, \\ Colin J Holman ${ }^{3}$, Donald A Wilson ${ }^{1,2,3}$ and Regina M Sullivan*, I,2,3 \\ 'Emotional Brain Institute, Nathan Kline Institute, Orangeburg, NY, USA; ${ }^{2}$ Child Study Center, Child \& Adolescent Psychiatry, New York University \\ School of Medicine, New York, NY, USA; ${ }^{3}$ Department of Zoology, University of Oklahoma, Norman, OK, USA
}

\begin{abstract}
Caregiver-associated cues, including those learned in abusive attachment, provide a sense of safety and security to the child. Here, we explore how cues associated with abusive attachment, such as maternal odor, can modify the enduring neurobehavioral effects of earlylife abuse. Two early-life abuse models were used: a naturalistic paradigm, where rat pups were reared by an abusive mother; and a more controlled paradigm, where pups underwent peppermint odor-shock conditioning that produces an artificial maternal odor through engagement of the attachment circuit. Animals were tested for maternal odor preference in infancy, forced swim test (FST), social behavior, and sexual motivation in adulthood - in the presence or absence of maternal odors (natural or peppermint). Amygdala odorevoked local field potentials (LFPs) via wireless electrodes were also examined in response to the maternal odors in adulthood. Both early-life abuse models induced preference for the maternal odors in infancy. In adulthood, these early-life abuse models produced FST deficits and decreased social behavior, but did not change sexual motivation. Presentation of the maternal odors rescued FST and social behavior deficits induced by early-life abuse and enhanced sexual motivation in all animals. In addition, amygdala LFPs from both abuse animal models showed unique activation within the gamma frequency $(70-90 \mathrm{~Hz})$ bands in response to the specific maternal odor present during early-life abuse. These results suggest that attachment-related cues learned during infancy have a profound ability to rescue neurobehavioral dysregulation caused by early-life abuse. Paradoxically, abuse-associated cues seem to acquire powerful and enduring antidepressive properties and alter amygdala modulation.
\end{abstract}

Neuropsychopharmacology (20I5) 40, 906-9|4; doi:I 0.I038/npp.20I4.266; published online 29 October 2014

\section{INTRODUCTION}

The caregiver and associated cues are thought to provide a sense of safety and security to the child (Bowlby, 1969). Paradoxically, even abusive attachments seem to provide some sense of safety and security, as indicated by proximity seeking and distress upon separation from the abusive caregiver (Carlson et al, 1989). Importantly, attachmentrelated cues, even when related to abusive-attachment, retain their value into adulthood (van der Kolk, 1989). This has been modeled in rodents, where both typical attachment cues (Fillion and Blass, 1986) and abusive attachment cues (Sevelinges et al, 2011) have the ability to modulate various behavioral systems later in life. Here, we model this association between attachment, safety signals, and

*Correspondence: Dr C Raineki, Cellular and Physiological Sciences, University of British Columbia, 2350 Health Sciences Mall, Vancouver, BC V6T IZ3, Canada, Tel: +604 822 4554,

E-mail: craineki@mail.ubc.ca. or R Sullivan, NYU Child Study Center, I Park Avenue, New York, NY I00 16, USA, Tel: 8453986692 ,

E-mail: regina.sullivan@nyumc.org

Received 12 May 2014; revised 21 September 2014; accepted 22 September 20।4; accepted article preview online 6 October 20।4; emotional programming in the rodent to explore the enduring value of cues associated with abusive attachment. Specifically, we use two different but complimentary models of early-life abuse to generate distinct maternal odors associated with the abuse and question whether the power of maternal odor learned through abusive attachment, which regulates infant behavior (Raineki et al, 2010; Sullivan and Holman, 2010), can later regulate adult neurobehavioral deficits programmed by that abuse.

The first model is a naturalistic paradigm, in which the mother is provided with insufficient bedding for nest building, leading to abusive maternal behavior (Raineki et al, 2010, 2012). The second model is an infant odorshock-conditioning paradigm, where a novel odor (ie, peppermint) paired with a mild electric shockmimicking pups' painful interactions with an abusive mother-acquires the value of a maternal odor, as it modulates pups' attachment-related behaviors (Camp and Rudy, 1988; Raineki et al, 2010; Sullivan et al, 2000). These two paradigms complement one another: the naturalistic paradigm provides ecological validity, whereas the conditioning provides experimental control over the infant experience, with both paradigms supporting infant 
attachment to the caregiver and resulting in similar enduring negative programing effects seen in adults (Raineki et al, 2012; Rincón-Cortés and Sullivan, 2014).

We hypothesize that cues associated with abusive attachment (natural and/or peppermint-conditioned maternal odor) acquire profound meaning in early life to control interactions with the mother, but also continue to exhibit neurobehavioral control throughout life in a way that is reminiscent of a safety signal, as it has the ability to modify amygdala function. The concept of a safety signal involves a learned association where a specific cue indicates safety from aversive stimuli, or even protection from danger in animal models (Josselyn et al, 2005; Hostinar et al, 2014; Kong et al, 2014; Ostroff et al, 2010; Pollak et al, 2008; Rogan et al, 2005) and in humans (Jovanovic et al, 2010; Pollak et al, 2010; Schiller et al, 2008). Safety signals can also be associated with attachment relationships formed throughout development (Eisenberger et al, 2011; Master et al, 2009). Previous work has shown that safety signals can reduce conditioned fear responses and rescue depressive-like behaviors by modulating amygdala activity (Kong et al, 2014; Pollak et al, 2008; Rogan et al, 2005; Schiller et al, 2008). Importantly, similar rescue effects were observed in adult rats that received odorshock conditioning during infancy, where the peppermintconditioned maternal odor normalized depressive-like behavior programmed by early-life abuse and modulated amygdala function (Sevelinges et al, 2011).

Here, we will test the hypothesis that the differential behavioral control of odors learned either during maternal abuse or peppermint odor-shock conditioning corresponds with differential, experience-dependent activation of the amygdala by these two odors. Specifically, we predict that the natural maternal odor associated with abuse will differentially activate amygdala circuits in abused animals, whereas peppermint will differentially activate the amygdala in odor-shock animals. Odor-evoked amygdala local field potential's (LFP) will be used to assess amygdala activation during odor stimulation. LFPs represent the summed synaptic activity within the region around the recording electrode. LFP oscillations can be divided into different frequency bands (theta, beta, and gamma) that are believed to reflect both different underlying cellular mechanisms and circuit functions (Buzsáki, 2006). Our analyses will include both fullspectrum assessments as well as a special focus on gamma frequency oscillations $(35-90 \mathrm{~Hz})$. Gamma frequency oscillations are commonly associated with reverberatory activity in local excitatory-inhibitory circuits, and are especially sensitive to GABAergic function (Cardin et al, 2009; Volman et al, 2011; Baldauf and Desimone, 2014), which we have previously shown to be involved in the mechanisms and consequences of early abusive learning (Thompson et al, 2008).

In summary, we will explore the enduring power of cues associated with abusive attachment to modulate depressivelike behavior, social behavior, sexual motivation, and amygdala odor-evoked LFP responses.

\section{MATERIALS AND METHODS}

\section{Subjects}

Male Long-Evans rats (Harlan) bred in our temperatureand light-controlled colony with ad libitum food and water were used. Procedures were approved by the Institutional Animal Care and Use Committee, which follows $\mathrm{NIH}$ guidelines. Additional details regarding materials and methods can be found in the Supplementary Section. A schematic outline of the experimental design is illustrated in Figure 1.

\section{Infant Abuse Paradigms}

Naturalistic abusive mother paradigm. Litters were housed in cages with limited nesting/bedding material (1 cm layer) from PN8-12. This bedding level is insufficient for nest building and results in maternal behavior changes, such as more frequent nest building attempts, more time out of nest, less nursing (ie nipple attachment), and rough handling of pups (ie aggressively grooming pups, transporting pups by limb, step/jump on pups). Despite reduced nursing, pups show normal weight gain. Mother and pup behaviors were recorded daily for $30 \mathrm{~min}$ from PN8-12 (Table 1).

Olfactory classical conditioning paradigm. From PN812, pups received daily odor-shock conditioning: 11 pairings of $30 \mathrm{~s}$ peppermint odor (McCormick) with a $0.5 \mathrm{~mA}$ hindlimb shock during the last $1 \mathrm{~s}$ of odor, with a 4 min intertrial interval (ITI). The odor was delivered by a flow dilution olfactometer at 2 liters/min flow rate and concentration of peppermint:air in 1:10 ratio.

Control group. Litters were housed in a cage with abundant (5-7 cm layer) bedding material; both mother and pups exhibited typical behaviors (Table 1).

\section{Infant Y-Maze Test}

At PN13, pups received a five-trial Y-maze test to measure odor approach. Odors in the two maze arms depended upon infant experience: (1) Control-(control mother reared) natural maternal odor $v s$ familiar odor (clean bedding); (2) Abusive mother-(abusive mother reared) natural maternal odor vs familiar odor; (3) Odor-shock-(peppermint odorshock conditioning) peppermint odor $v s$ familiar odor; (4) Neutral odor-(control mother reared) peppermint odor (no value) vs familiar odor. Maternal odor was delivered via olfactometer at 2 liters/min air:odor in the ratio $1: 1$, peppermint odor was delivered by $20 \mu \mathrm{l}$ of peppermint on a Kim-wipe, and the familiar odor was clean bedding in a petri dish.

\section{Adult Behavioral Tests}

Forced swim test $(F S T)$. A clean tank $(30 \times 24 \times 47.5 \mathrm{~cm})$ filled with water $\left(25 \pm 1{ }^{\circ} \mathrm{C}\right.$; depth prevented escape and tailtouching bottom) was used for each animal. Animals were habituated $(15 \mathrm{~min})$ and then tested $(5 \mathrm{~min})$ the following day. Testing was recorded and time spent immobile measured (passive floating without struggling, slightly hunched but upright position with minor movements to maintain head above water).

During testing, half of the animals in each group received a continuous presentation of either natural or peppermintconditioned maternal odor. A Plexiglas lid covered the FST 


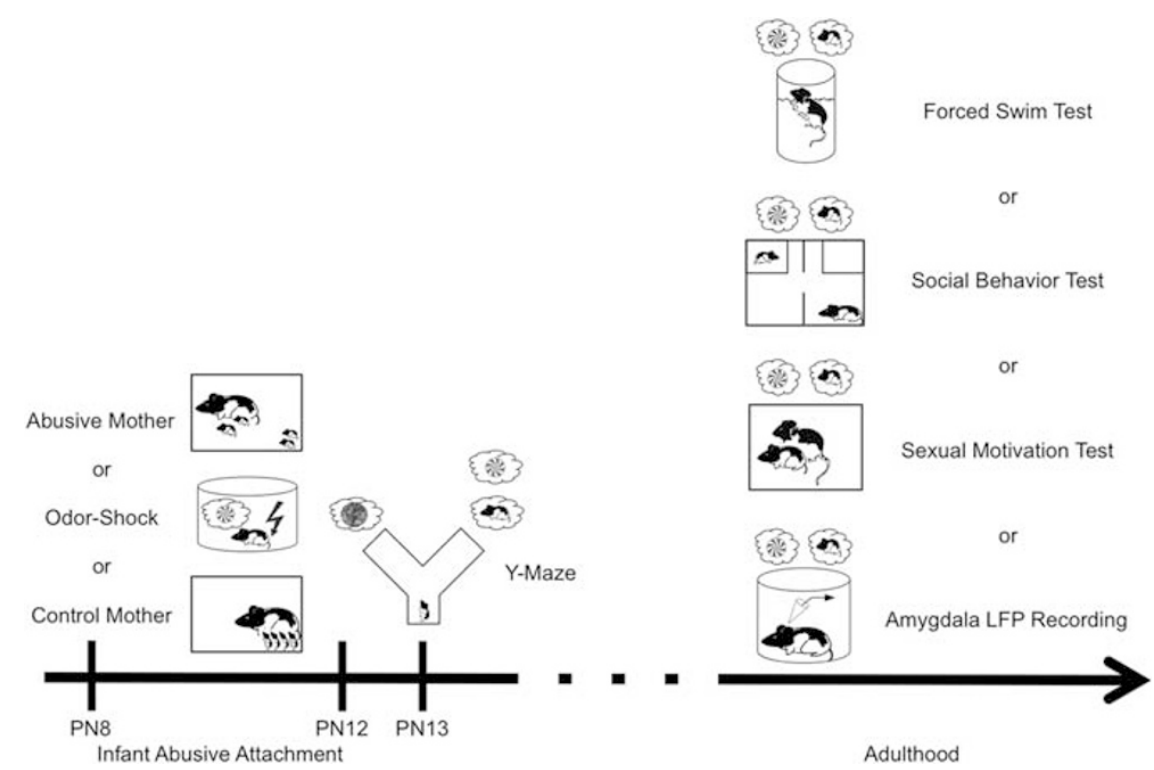

Figure I Schematic figure outlining experimental design. From PN8-12, pups were reared either by a control mother, a naturally abusive mother, or received daily odor-shock conditioning. Animals were used for only one test. At PNI3, some pups were tested in the Y-maze, whereas others were permitted to reach adulthood and given a forced swim test (FST), social behavior test, or sexual motivation test with or without continuous presentation of the natural (for control and abused animals) or peppermint-conditioned maternal odor (for odor-shock conditioned animals) maternal odor. The remaining animals were used to record amygdala local filed potentials (LFP) using telemetry in response to the natural and peppermint-conditioned maternal odor.

Table I Maternal and Pup Behaviors Observed During Mother-Infant Interactions in the Naturalistic Abuse Rearing Infant Procedure

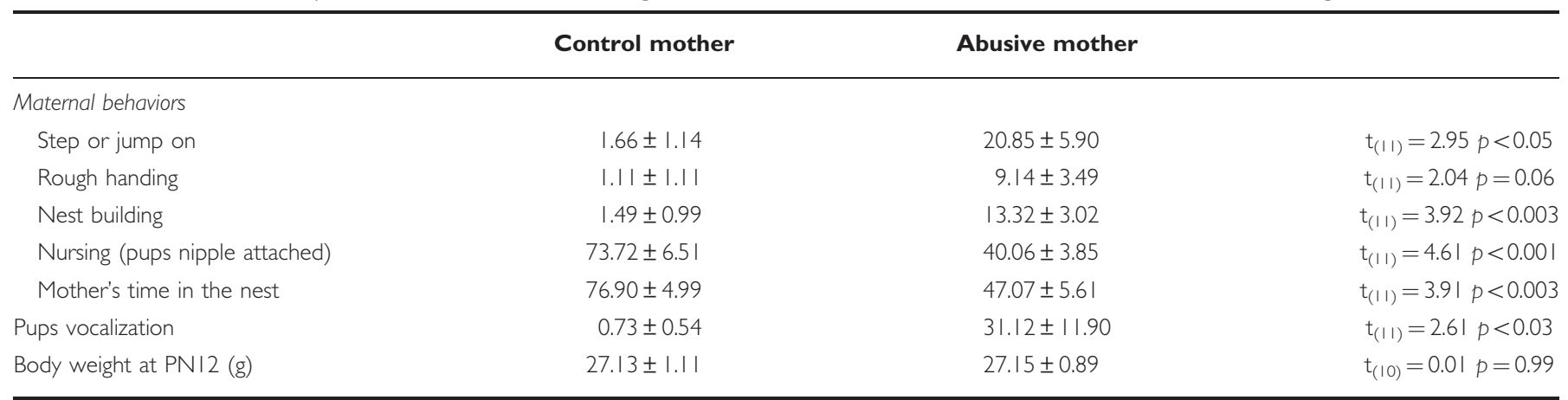

For maternal behavior and pups vocalization, the data are presented as mean of the percentage ( \pm SEM) of the time or frequency of the observed behavior. The body weight (mean $\pm \mathrm{SEM}$ ) is presented in grams.

apparatus to ensure the odor did not dissipate. The control and abusive mother groups were presented natural maternal odor, whereas the peppermint odor-shock group received the peppermint-conditioned maternal odor. For the natural maternal odor presentations, two anesthetized mothers were placed in an airtight glass jar connected to a flow dilution olfactometer (10 liters/min flow rate-odor:air in the ratio 1:1). For the peppermint-conditioned maternal odor presentations, the peppermint odor was delivered by a flow dilution olfactometer ( 2 liters/min flow rate-odor:air in the ratio $1: 10$ ).

Social behavior test. A black Plexiglas box $(60 \times 60 \times 70$ $\mathrm{cm}$ ) was divided into two equal chambers by a sheet of black Plexiglas with a small opening $(15 \times 13 \mathrm{~cm})$ to permit movement between chambers. A metal grid cube
$(15 \times 15 \times 15 \mathrm{~cm})$ was placed within each chamber. The test animal was given a $5 \mathrm{~min}$ acclimation period and then a younger, same sex animal (PN 28-38) was placed inside one of the metal cubes to start the $10 \mathrm{~min}$ test. As described in the FST, half the animals in each group received either the natural or peppermint-conditioned maternal odor.

Sexual motivation test. Sexual motivation was assessed in a Plexiglas test box $(26 \times 50 \times 30 \mathrm{~cm})$ under red lights after the dark cycle onset. The adult male was given a $10 \mathrm{~min}$ adaptation period to the enclosure prior to introducing the sexually receptive female rat, and the number of mounts recorded during $10 \mathrm{~min}$. As described above, half the animals in each group received either natural or peppermint-conditioned maternal odor. 


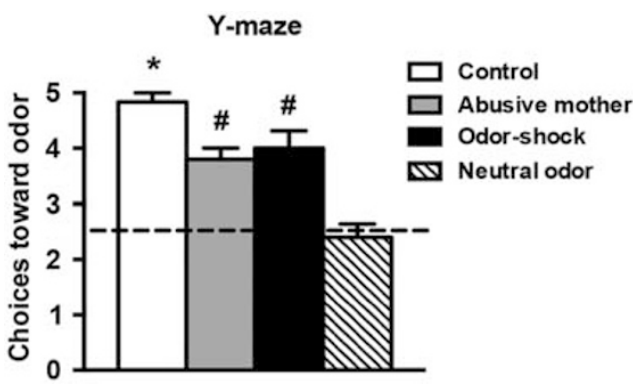

Figure 2 At PNI3, pups were given a Y-maze test to assess preference for odors experienced during infant rearing or odor-shock conditioning. One arm of the maze always contained the familiar odor of clean wood shavings used for bedding (side randomly determined at each test). The other arm contained an odor that differed between groups: (I) Controlpups reared by a control mother were given the choice between natural maternal odor vs the familiar odor and showed a preference for the maternal odor; (2) Abusive mother-pups reared with an abusive mother received testing with natural maternal odor vs the familiar odor and also showed a preference for the natural maternal odor; (3) Odor-shock-pups that received daily conditioning with peppermint odor and shock were tested with peppermint odor vs the familiar odor and showed a preference for the peppermint odor; and (4) Neutral odor-pups reared by a control mother were tested with peppermint odor (odor with no value for this group as the animals had no previous experience with the odor) vs familiar odor (clean shavings) and showed no preference for either odor. $* P<0.05$, significant difference from all other groups; ${ }^{\#} P<0.05$, significant difference from neutral odor group ( $n=5-6$ per group).

\section{Adult Amygdala Wireless LFP Recordings}

A detailed description of experimental procedures and analysis for the adult LFP recordings can be found in the Supplementary Section and in Sarro et al, 2014. Briefly, the animals were anesthetized (isoflurane), placed in a stereotaxic, and the recording electrode implanted (bipolar teflon coated $0.18-\mathrm{mm}$ diameter stainless-steel electrode) targeting the left amygdala complex ( $2.3 \mathrm{~mm}$ posterior from bregma; $5.0 \mathrm{~mm}$ lateral; lowered $8.0 \mathrm{~mm}$ ventral from brain surface). The electrode was connected to a telemetry pack (DSI) inserted subcutaneously on the animal's back. Animals recovered for 1 week. LFP recordings in response to the natural or peppermint-conditioned maternal odor were recorded via telemetry in freely behaving rats. For a typical recording section, the animal was placed in a small cage in a sound-attenuated recording booth and amygdala LFP activity was recorded continuously throughout a $5 \mathrm{~min}$ habituation, followed by five presentations of a $5 \mathrm{~s}$ odor with 5 min ITI. Each animal received one session with natural maternal odor and another session with peppermint odor at least $3 \mathrm{~h}$ later. Odors were presented with computercontrolled olfactometers. Odors were not matched for intensity, but were both easily detectable by humans. Neural signals were amplified, filtered $(0.5-300 \mathrm{~Hz})$, digitized at $2 \mathrm{kHz}$ with Spike2 software (CED, Inc) and analyzed offline. As in our previous work (Sarro et al, 2014), recordings were all from the left amygdala. It has been suggested occasional lateral asymmetry in rodent amygdala functions (Tran and Greenwood-Van Meerveld, 2012) and this will be assessed in future work. After the recordings, the brains were removed, sectioned, and stained to verify electrode placement.

\section{Statistical Analysis}

Behavioral data were expressed as means ( \pm SEM). Table 1 data were analyzed using Student's $t$-test. Pup and adult data were analyzed by one-way ANOVA and two-way ANOVA (infant condition and maternal odor presentation as factors), respectively and followed by post hoc Fisher tests. In all cases, differences were considered significant when $P<0.05$.

For the LFP data, fast fourier transform power analyses were performed on the raw data in intervals taken from each session's neural trace immediately before and during each odor presentation, permitting quantifying LFP oscillatory power in $2.4 \mathrm{~Hz}$ frequency bins from $0-100 \mathrm{~Hz}$ (Hanning). Power in the theta $(5-15 \mathrm{~Hz})$, beta $(15-35 \mathrm{~Hz})$ and gamma $(35-90 \mathrm{~Hz})$ frequency bands was calculated for each specified window. Odor-evoked change in LFP oscillatory power was calculated as percent change in power from baseline activity during the $5 \mathrm{~s}$ before odor presentation to $5 \mathrm{~s}$ during odor presentation in each frequency band. Repeated measures ANOVA's were run to test for main effects of odor type on odor-evoked response, followed by post hoc analyses to examine differences between specific LFP frequencies.

\section{RESULTS}

\section{Infant Y-Maze Test}

The Y-maze test results showed that pups reared by an abusive mother or that received infant odor-shock conditioning exhibited an odor preference to the natural or peppermint-conditioned maternal odor, respectively (Figure 2). ANOVA analysis revealed a significant effect for infant condition $\left(\mathrm{F}_{(3,20)}=19.230, P<0.0001\right)$. Post hoc Fisher tests revealed that across all conditions, animals showed a significant preference for the maternal odor when compared with a group of animals that had the choice between a neutral and a familiar odor-the neutral odor group. Animals raised by control mothers showed a significantly higher approach response than animals from both early-life abuse paradigms.

\section{Adult Behavioral Tests}

Forced swim test. Being reared by an abusive mother or receiving odor-shock conditioning during infancy induced depressive-like behavior, as indicated by an increase in time spent immobile relative to control animals (Figure 3a). Importantly, the natural or the peppermint-conditioned maternal odor exposure during the FST was able to rescue the depressive-like behavior in both models of early-life abuse. ANOVA analysis revealed a significant interaction between infant condition and maternal odor presence $\left(\mathrm{F}_{(2,26)}=14.643, P<0.0001\right)$. Moreover, significant main effects of infant condition $\left(\mathrm{F}_{(2,26)}=22.293, P<0.0001\right)$ and maternal odor presence $\left(\mathrm{F}_{(1,26)}=48.766, P<0.0001\right)$ were also detected. Post hoc Fisher tests for the interaction revealed that animals reared by an abusive mother and animals that received odor-shock conditioning during infancy spent significantly more time immobile than control animals. However, the time spent immobile in animals from both abuse models tested with either the natural or the 
a

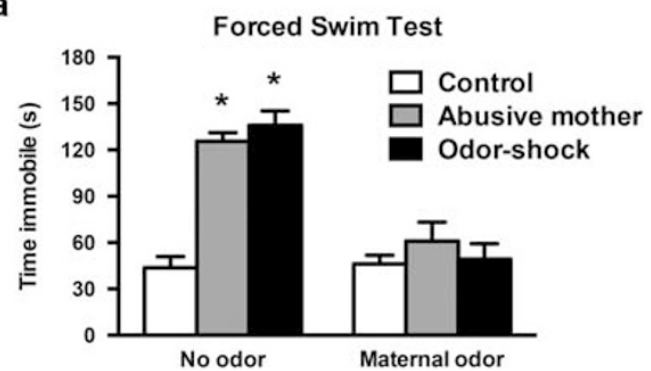

b

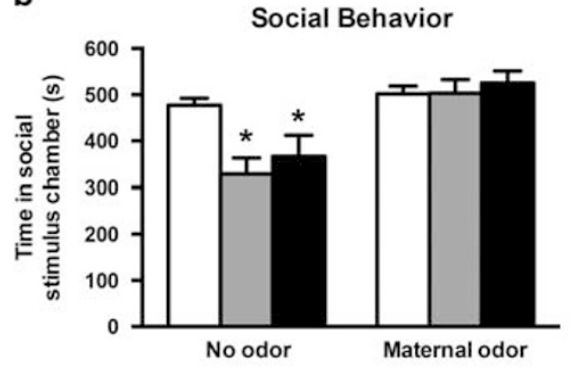

c

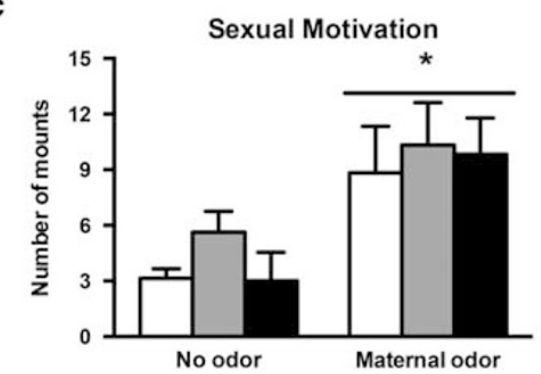

Figure 3 In adulthood, animals were given a forced swim test (a), social behavior test (b), and sexual motivation test (c) with or without continuous presentation of the natural maternal odor (for control and abusive mother rearing animals) or peppermint-conditioned maternal odor (for odor-shock conditioned animals). In the FST (a), animals from both abuse paradigms spent significantly more time immobile when compared with control rats; however, maternal odor presentation rescued this depressive-like behavior. $* P<0.05$, significant difference from each group ( $n=4-6$ per group). In the social behavior test (b), animals from both abuse paradigms spent significantly less time interacting with the social stimulus when compared with control rats; however, maternal odor presentation rescued this social behavior deficit. $* P<0.05$, significant difference from each group ( $n=5-9$ per group). In the sexual motivation test (c), none of the abuse paradigms induced deficits in the number of mounts when compared with control rats; however, maternal odor presentation increased the number of mounts in all groups. $* P<0.05$, significant difference from each group ( $n=5-1$ I per group).

peppermint-conditioned maternal odor exposure did not differ from control animals tested with or without odor exposure.

Social behavior test. Being reared by an abusive mother or receiving odor-shock conditioning during infancy impaired social interactions in adulthood compared with control animals (Figure 3b). Natural or peppermint-conditioned maternal odor exposure during the social behavior test rescued the social interaction deficits in all early-life abuse groups. ANOVA analysis revealed a significant interaction between infant condition and maternal odor presence $\left(\mathrm{F}_{(2,34)}=5.230, P<0.01\right)$. Moreover, significant main effects of infant condition $\left(\mathrm{F}_{(2,34)}=3.911, P<0.02\right)$ and maternal odor presence $\left(\mathrm{F}_{(1,34)}=28.082, P<0.0001\right)$ were also detected. Post hoc Fisher tests for the interaction revealed that animals from both early-life abuse groups spent significantly less time in the chamber with the social stimulus than control animals. However, the time spent in the chamber with the social stimulus in animals from both abuse models tested with natural or the peppermint-conditioned maternal odor exposure did not differ from control animals tested with or without odor exposure.

Sexual motivation test. Being reared with an abusive mother or receiving odor-shock conditioning during infancy did not change later life sexual motivation. However, the natural or peppermint-conditioned maternal odor presentation increased the number of mounts in all groups analyzed (Figure 3c). ANOVA analysis revealed no significant interaction between infant condition and odor presence $\left(\mathrm{F}_{(2,37)}=1.338\right)$, and no significant main effect of infant condition $\left(\mathrm{F}_{(2,37)}=1.178\right)$. However, a significant main effect of maternal odor presence $\left(\mathrm{F}_{(1,37)}=15.302\right.$; $P<0.0003$ ) was detected. Post hoc Fisher tests revealed that the presence of natural or peppermint-conditioned maternal odor significantly increased the number of mounts in all animals independent of infant condition.

\section{Amygdala LFP Responses}

Being reared by an abusive mother or receiving odor-shock conditioning during infancy led to differential amygdala neural responses to the maternal odor when compared with control animals (Figure 4). At baseline, pre-odor LFP activity was not significantly different across conditions $\left(\mathrm{F}_{(1,1227)}=2.06 ; P=0.10\right)$, which allowed us to present the magnitude of LFP response to each odor as a percent change from the pre-odor period and compare this magnitude change across conditions. Animals that received peppermint odor-shock conditioning during infancy displayed an odor-specific enhancement in amygdala activation in response to the peppermint-conditioned maternal odor when compared with the amygdala response of control animals to peppermint (Figure $4 \mathrm{a}$ and $\mathrm{c}$; $\mathrm{F}_{(1,1228)}=8.27$; $P<0.01)$. Post hoc analyses revealed specific increases in the percent change of LFP activity only within the high gamma frequency range $(\sim 70-90 \mathrm{~Hz})$ that was specific for those animals with odor-shock conditioning during infancy (Figure 4e; $\left.\mathrm{F}_{(1,19)}=4.75 ; P<0.05\right)$. In comparison, in those animals reared by an abusive mother, high gamma LFP activity in response to peppermint was not different from controls $\left(t_{(1,14)}=0.23, P=0.8\right)$. In contrast, animals reared by an abusive mother displayed an odor-specific enhancement in amygdala activation in response to the natural maternal odor when compared with the response of control animals to the natural maternal odor (Figure $4 \mathrm{~b}$ and d; $\left.\mathrm{F}_{(1,1638)}=15.3 ; \quad P<0.0001\right)$. Post hoc analyses revealed specific increases in the percent change of LFP activity only within a similar high gamma frequency range $(\sim 70-$ $90 \mathrm{~Hz}$ ). Again, the enhancement in the gamma band activity range was specific to those animals reared with an abusive mother (Figure 4f; $\mathrm{F}_{(1,19)}=3.68 ; P<0.05$ ). In comparison, in those animals with early peppermint odor-shock conditioning, high gamma LFP activity in response to the natural maternal odor was not different from controls $\left(t_{(1,14)}=0.34\right.$; 
a

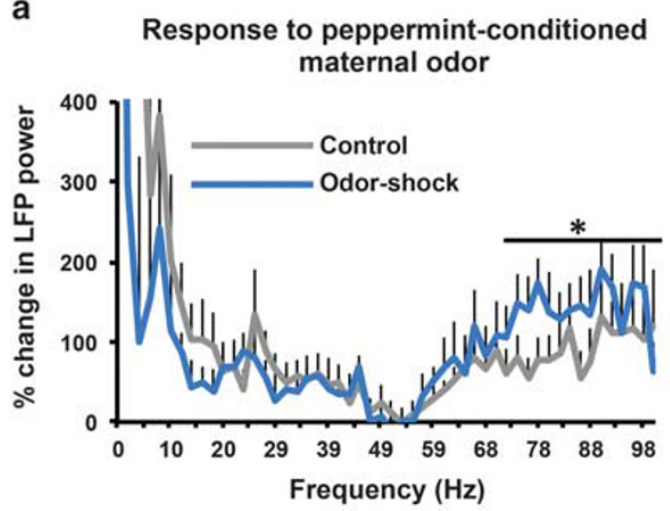

C

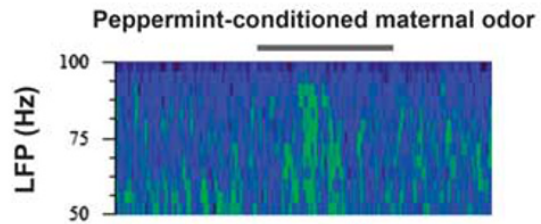

High gamma LFP $(70-90 \mathrm{~Hz})$

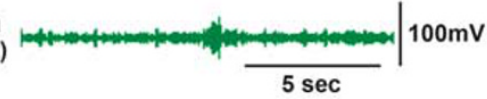

e

Gamma response to peppermint-conditioned maternal odor

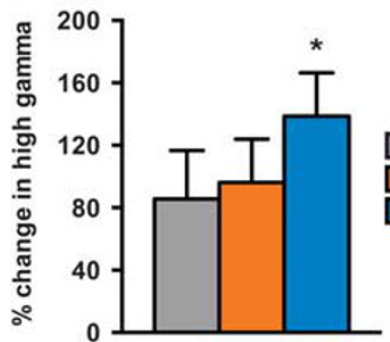

b

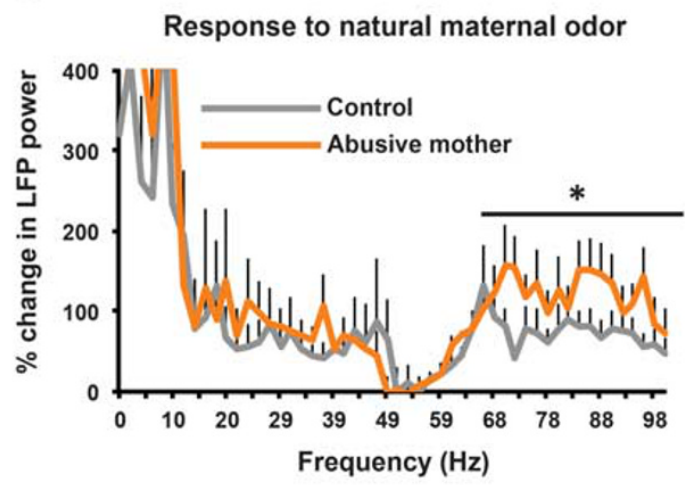

d

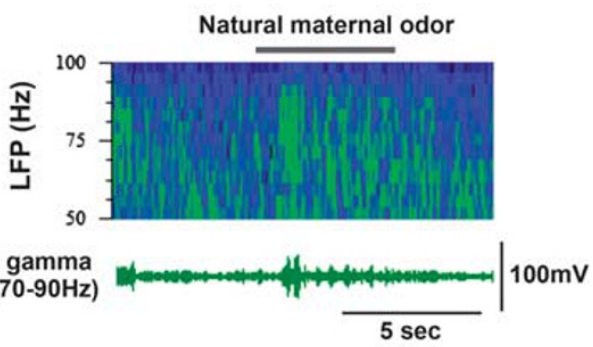

f

Gamma response to natural maternal odor

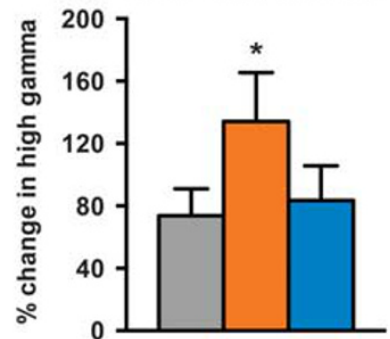

Figure 4 Adult animals that were reared by a naturally abusive mother or that received daily peppermint odor-shock conditioning from PN8-12 displayed odor-specific enhancement in amygdala LFP responses to the odor associated with the early-life abuse. Average percent change in power across LFP frequency $(\mathrm{Hz})$ when comparing LFP activity before and during the odor presentation ( $\mathrm{a}$ and b). Animals that received daily odor-shock conditioning during infancy (a, blue line) or were reared by a naturally abusive mother (b, orange line) show greater LFP activity within gamma band frequencies to the abuse-related odor (natural or peppermint-conditioned maternal odor) than control adults (gray line). Example sonograms (c and d, top) and neural traces (c and d, bottom), filtered to show specifically the $70-90 \mathrm{~Hz}$ response, are taken from an animal that received odor-shock conditioning in infancy during the presentation of the peppermintconditioned maternal odor (c) and from an animal reared with a naturally abusive mother during the presentation of the natural maternal odor (d). Gray line shows the time when the peppermint (c) or natural maternal (d) odor was presented. The enhanced gamma frequency response was specific to the odor associated with infant abuse. Bar graphs show the percent change in LFP gamma band activity $(70-90 \mathrm{~Hz})$ in response to the peppermint-conditioned maternal odor (e) and the natural maternal odor ( $f$. Animals that received daily peppermint odor-shock conditioning in infancy had an enhanced response to peppermint but not to natural maternal odor, whereas animals that were reared by a naturally abusive mother had enhanced amygdala response to natural maternal odor but not peppermint. $* P<0.05$, significant difference from each group and error bars are SEM $(n=6-10$ per group).

$P=0.7)$. The observed LFP changes were limited to the gamma frequency band. There were no significant differences across animal conditions for either theta or beta oscillation frequency bands (response to peppermint: Theta: $\mathrm{F}_{(1,19)}=1.2 ; P=0.3$; Beta: $\mathrm{F}_{(1,19)}=0.22 ; P=0.8$; response to natural maternal odor; Theta: $\mathrm{F}_{(1,17)}=0.43, P=0.7$; Beta: $\left.\mathrm{F}_{(1,17)}=0.56 ; P=0.6\right)$.

\section{DISCUSSION}

Our results show for the first time that cues associated with abusive attachment can function as a safety signal to rescue the neurobehavioral deficits produced by early-life abuse. Specifically, odors associated with infant abuse rescue deficits in depressive-like behavior (FST) and social behavior, and modify amygdala function as assessed by LFP recordings. This was shown not only in an ecologically relevant paradigm involving a naturally abusive mother, but also in a controlled peppermint odor-shock conditioning paradigm, which has previously shown to be associated with attachment (Raineki et al, 2010). Importantly, the ability of the infant odors to produce behavioral rescue of depressivelike behavior converge with results from learned safety signal literature. 
Modulation of Adult Behavior by Odors Associated with Abusive Attachment

The data presented here suggest that whereas infant rats likely benefit from attachment formation under adverse conditions in the short term, the long-term effects appear to be detrimental. Specifically, both early-life abuse models led to depressive-like behavior in adulthood as measured by FST and social behavior test. Moreover, our behavioral results are consistent with both clinical studies and those in animal models, demonstrating the enduring negative effects of early-life adversity on adult emotionality (Bale et al, 2010; Heim et al, 2010; Malter-Cohen et al, 2013; McEwen, 2008).

Importantly, it has been shown that attachment-related cues can retain their value into adulthood, as maternal odors learned in typical attachment alter various behavioral systems, including those supporting reproduction (our control animals; Fillion and Blass, 1986) and food choice (Leon et al, 1977). Here, we demonstrated that both natural and peppermint-conditioned maternal odor rescued adult depressive-like behaviors following early-life abuse. These findings corroborate previous results from our laboratory using infant odor shock, in which the odor learned during infancy rescued deficits in the FST and sucrose consumption test (Sevelinges et al, 2011). The present work expands these results by introducing a naturalistic model of early-life abuse that provides ecological validity and relevance to the infant olfactory classical conditioning paradigm. Our results indicate that, like the peppermint-conditioned maternal odor, the natural maternal odor can rescue social and depressive-like behavioral deficits in animals reared in a naturalistic model of early-life abuse. Together, these results suggest that socially relevant cues learned in an abusive attachment during infancy can have a positive effect in modulating psychopathologies, such as depression.

We suggest that the natural and peppermint-conditioned maternal odors learned during abusive attachment in infancy acquire the value of a safety signal, which has previously been shown to reduce conditioned fear responses and rescue depressive-like behaviors in the FST (Kong et al, 2014; Pollak et al, 2008; Rogan et al, 2005; Schiller et al, 2008). Our results from both models of early-life abuse support the idea of maternal odor as a safety signal in infancy and adulthood. Specifically, both models of earlylife abuse induce a paradoxical preference for the abusive maternal odor-a preference that persists into adulthood (Sevelinges et al, 2011). Moreover, the natural and peppermint-conditioned maternal odors were able to rescue depressive-like behaviors (our results; Sevelinges et al, 2011) and reduce conditioned fear responses (Sevelinges et al, 2007, Moriceau et al, 2009). Together, these results indicate that the well-described preference in infancy for the potentially aversive stimulus, such as the abusive mother (Raineki et al, 2010), can generate a potential safety signal later in life that may have clinical applications.

Conversely, neither of early-life abuse models altered the number of mounts, suggesting that sexual motivation may be spared. These results diverge from other experimental models such as neonatal handling (Padoin et al, 2001) or variations in maternal licking of pups (Cameron et al, 2008), in which long-term changes in sexual behavior and motivation were observed. However, our data indicate that the maternal odor (natural or peppermint-conditioned) was able to enhance sexual motivation in all groups analyzed, regardless of the quality of infant attachment. These data complement previous results demonstrating that maternal odor learned in a typical attachment enhances behaviors related to sexual performance, including mounts (Fillion and Blass, 1986). In addition, it seems that social cues learned in a typical and/or abusive attachment during infancy act through the same neural system to modulate sexual motivation; however, the exact mechanisms are still unknown.

\section{Modulation of Adult Amygdala Activity by Odors Associated with Abusive Attachment}

Odors associated with abusive attachment are able to induce a unique amygdala LFP response in adulthood. Specifically, the amygdala displayed greater gamma frequency oscillations in response to the unique odor associated with abuse during infancy-natural maternal odor for animals with an abusive mother and peppermint-conditioned maternal odor for animals that received odor-shock conditioning in infancy. Gamma frequency oscillations are thought to reflect local circuit activity (Buzsáki, 2006), and are especially sensitive to GABAergic inhibitory interneuron function in many brain areas (Lasztóczi and Klausberger, 2014; Traub et al, 1996), including the amygdala (Sinfield and Collins, 2006). Thus, the odor-specific enhancement of amygdala gamma oscillations to the odor learned during abusive experience in infancy may reflect long-lasting changes in amygdala GABAergic function. In fact, previous work has demonstrated changes in amygdala paired pulse inhibition following early-life abusive experience, which also implicates a change in GABAergic circuitry (Sevelinges et al, 2007, 2011; Rincón-Cortés et al, unpublished observations).

These electrophysiological results support prior work demonstrating that early-life abuse can induce long-term changes in amygdala function and amygdala-dependent behaviors in both humans (Tottenham, 2013) and animal models (Hill et al, 2014; Raineki et al, 2012; Sevelinges et al, 2007, 2011). This could be due in part to the precocious activation of the amygdala during a period when it is undergoing rapid developmental change and is vulnerable (Lupien et al, 2009; Moriceau et al, 2006). Indeed, amygdala GABAergic function undergoes dramatic developmental changes during the period in which the animals used in the present study were exposed to early-life abuse (Thompson et al, 2008; Ehrlich et al, 2013).

In addition, gamma oscillations have been associated with cognitive functions such as attention, integration of sensory and multisensory signals, and memory formation (Engel et al, 2001; Jensen et al, 2007). In the amygdala, there are enhanced gamma oscillations in response to learned stimuli (Headley and Weinberger, 2013) and evidence suggests that they may coordinate local amygdala neural activity with activity in other corticolimbic areas (Bauer et al, 2007). Exactly how the odor-specific modification of amygdala activation observed here translates into differential behavioral responses is not clear. However, our identification of this odor-specific physiological signature of amygdala response to stimuli associated with early-life abuse and safety signals may provide an opportunity to 
identify specific cellular mechanisms of this form of emotional memory.

\section{Implications}

Attachment-related cues learned during infancy have the profound ability to rescue neurobehavioral dysregulation caused by early-life abuse, suggesting that these abuserelated cues paradoxically have potent and enduring safety signal value. The discovery that infant cues associated with abusive attachment can retain their value throughout the life span is of great interest because it suggests an opportunity for intervention and possibly correction of maladaptive outcomes related to psychopathology induced by adverse early-life experiences within attachment. These results also may provide some insight into why early-life abuse cues are approached and revisited.

\section{FUNDING AND DISCLOSURE}

The authors declare no conflict of interest.

\section{ACKNOWLEDGEMENTS}

This research was supported by NIH-NIMH MH091451 and NIH-DC009910 to RMS and DW, NSF Graduate Research Fellowship DGE-1137475 to MRC, and REP was supported by T32 MH096331 to NYU School of Medicine.

\section{REFERENCES}

Baldauf D, Desimone R (2014). Neural mechanisms of object-based attention. Science 344: 424-427.

Bale TL, Baram TZ, Brown AS, Goldstein JM, Insel TR, McCarthy MM et al (2010). Early life programming and neurodevelopmental disorders. Biol Psychiatry 68: 314-319.

Bauer EP, Paz R, Paré D (2007). Gamma oscillations coordinate amigdalo-rhinal interactions during learning. J Neurosci 27: 9369-9379.

Bowlby J (1969). Attachment and loss (Basic Books: New York, NY, USA (Vol 1).

Buzsáki G (2006). Rhythms of the brain. Oxford University Press: New York, NY, USA.

Cameron N, Del Corpo A, Diorio J, McAllister K, Sharma S, Meaney MJ (2008). Maternal programming of sexual behavior and hypothalamic-pituitary-gonadal function in the female rat. PLoS One 3: e2210.

Camp LL, Rudy JW (1988). Changes in the categorization of appetitive and aversive events during postnatal development of the rat. Dev Psychobiol 21: 25-42.

Carlson V, Cicchetti D, Barnett D, Braunwald K (1989). Finding order in disorganization: Lessons on maltreated infants' attachment to their caregivers. In: Cicchetti D, Carlson V (eds). Child Maltreatment: Theory and Research on the Causes and Consequences of Child Abuse and Neglect. John Wiley \& Sons: Chichester, UK, pp 57-85.

Cardin JA, Carlén M, Meletis K, Knoblich U, Zhang F, Deisseroth K et al (2009). Driving fast-spiking cells induces gamma rhythm and controls sensory responses. Nature 459: 663-668.

Engel AK, Fries P, Singer W (2001). Dynamic predictions: oscillations and synchrony in top-down processing. Nat Rev Neurosci 2: 704-716.
Ehrlich DE, Ryan SJ, Hazra R, Guo JD, Rainnie DG (2013). Postnatal maturation of GABAergic transmission in the rat basolateral amygdala. J Neurophysiol 110: 926-941.

Eisenberger NI, Master SL, Inagaki TK, Taylor SE, Shirinyan D, Lieberman MD et al (2011). Attachment figures activate a safetysignal related neural region and reduce pain experience. Proc Natl Acad Sci USA 108: 11721-11726.

Fillion TJ, Blass EM (1986). Infantile experience with suckling odors determines adult sexual behavior in male rats. Science 231: 729-731.

Headley DB, Weinberger NM (2013). Fear conditioning enhances $\gamma$ oscillations and their entrainment of neurons representing the conditioned stimulus. J Neurosci 33: 5705-5717.

Heim C, Shugart M, Craighead WE, Nemeroff CB (2010). Neurobiological and psychiatric consequences of child abuse and neglect. Dev Psychobiol 52: 671-690.

Hill KT, Warren M, Roth TL (2014). The influence of infantcaregiver experiences on amygdala Bdnf, OXTr, and NPY expression in developing and adult male and female rats. Behav Brain Res 22: 175-280.

Hostinar CE, Sullivan RM, Gunnar MR (2014). Psychobiological mechanisms underlying the social buffering of the hypothalamic-pituitary-adrenocortical axis: a review of animal models and human studies across development. Psychol Bull 140: 256-282.

Jensen O, Kaiser J, Lachaux JP (2007). Human gamma-frequency oscillations associated with attention and memory. Trends Neurosci 30: 317-324.

Josselyn SA, Falls WA, Gewirtz JC, Pistell P, Davis M (2005). The nucleus accumbens is not critically involved in mediating the effects of a safety signal on behavior. Neurophsychopharmacology 30: $17-26$.

Jovanovic T, Norrholm SD, Blanding NQ, Davis M, Duncan E, Bradley B et al (2010). Impaired fear inhibition is a biomarker of PTSD but not depression. Depress Anxiety 27: 244-251.

Kong E, Monje FJ, Hirsch J, Pollak DD (2014). Learning not to fear: neural correlates of learned safety. Neurophsychopharmacology 39: 515-527.

Lasztóczi B, Klausberger T (2014). Layer-specific GABAergic control of distinct gamma oscillations in the CA1 hippocampus. Neuron 81: 1126-1139.

Leon M, Galef BG, Behse JH (1977). Establishment of pheromonal bonds and diet choice in young rats by odor pre-exposure. Physiol Behav 18: 387-391.

Lupien SJ, McEwen BS, Gunnar MR, Heim C (2009). Effects of stress throughout the lifespan on the brain, behaviour and cognition. Nat Rev Neurosci 10: 434-445.

Malter-Cohen M, Jing D, Yang RR, Tottenham N., Lee FS, Casey BJ (2013). Early-life stress has persistent effects on amygdala function and development in mice and humans. Proc Natl Acad Sci USA 110: 18274-18278.

Master SL, Eisenberger NI, Taylor SE, Naliboff BD, Shirinyan D, Lieberman MD (2009). A picture's worth: Partner photographs reduce experimentally induced pain. Psychol Sci 29: 1316-1318.

McEwen BS (2008). Understanding the potency of stressful earlylife experiences on brain and body function. Metabolism 57: S11-S15.

Moriceau S, Raineki C, Holman JD, Holman JG, Sullivan RM (2009). Enduring neurobehavioral effects of early-life trauma mediated through learning and corticosterone suppression. Front Behav Neurosci 3: 22.

Moriceau S, Wilson DA, Levine S, Sullivan RM (2006). Dual circuitry for odor-shock conditioning during infancy: Corticosterone switches between fear and attraction via amygdala. $J$ Neurosci 26: 6737-6748.

Ostroff LE, Cain CK, Bedont J, Monfils MH, LeDoux JE (2010). Fear and safety learning differentially affects synapse size and dendritic translation in the lateral amygdala. Proc Natl Acad Sci USA 107: 9418-9423. 
Padoin MJ, Cadore LP, Gomes CM, Barros HMT, Lucion AB (2001). Long-lasting effects of neonatal stimulation on the behavior of rats. Behav Neurosci 115: 1332-1340.

Pollak DD, Monje FJ, Zuckerman L, Denny CA, Drew MR, Kandel ER (2008). An animal model of a behavioral intervention for depression. Neuron 60: 149-161.

Pollak DD, Rogan MT, Egner T, Perez DL, Yanagihara TK, Hirsch J (2010). A translational bridge between mouse and human models of learned safety. Ann Med 42: 115-122.

Raineki C, Moriceau S, Sullivan RM (2010). Developing a neurobehavioral animal model of infant attachment to an abusive caregiver. Biol Psychiatry 67: 1137-1145.

Raineki C, Rincón-Cortés M, Belnoue L, Sullivan RM (2012). Effects of early-life abuse differ across development: Infant social behavior deficits are followed by adolescent depressive-like behaviors mediated by the amygdala. J Neurosci 32: 7758-7765.

Rincón-Cortés M, Sullivan RM (2014). Early life trauma and attachment: immediate and enduring effects on neurobehavioral and stress axis development. Front Endocrinol 5: 33.

Rogan MT, Leon KS, Perez DL, Kandel ER (2005). Distinct neural signatures for safety and danger in the amygdala and striatum of the mouse. Neuron 46: 309-320.

Sarro EC, Wilson DA, Sullivan RM (2014). Maternal regulation of infant brain state. Curr Biol 24: 1664-1669.

Schiller D, Levy I, Niv Y, LeDoux JE, Phelps EA (2008). From fear to safety and back: Reversal of fear in the human brain. $J$ Neurosci 28: 11517-11525.

Sevelinges Y, Moriceau S, Holman P, Miner C, Muzny K, Gervais R et al (2007). Enduring effects of infant memories: infant odorshock conditioning attenuates amygdala activity and adult fear conditioning. Biol Psychiatry 62: 1070-1079.
Sevelinges Y, Mouly AM, Raineki C, Moriceau S, Forest C, Sullivan RM (2011). Adult depression-like behavior, amygdala and olfactory cortex functions are restored by odor previously paired with shock during infant's sensitive period attachment learning. Dev Cog Neurosci 1: 77-87.

Sinfield JL, Collins DR (2006). Induction of synchronous oscillatory activity in the rat lateral amygdala in vitro is dependent on gap junction activity. Eur J Neurosci 24: 3091-3095.

Sullivan RM, Holman PJ (2010). Transitions in sensitive period attachment learning in infancy: The role of corticosterone. Neurosci Biobehav Rev 34: 835-844.

Sullivan RM, Landers M, Yeaman B, Wislon DA (2000). Good memories of bad events in infancy. Nature 407: 38-39.

Thompson JV, Sullivan RM, Wilson DA (2008). Developmental emergence of fear learning corresponds with changes in amygdala synaptic plasticity. Brain Res 1200: 58-65.

Tottenham N (2013). The importance of early experiences for neuro-affective development. Curr Top Behav Neurosci 16: 109-129.

Tran L, Greenwood-Van Meerveld B (2012). Lateralized amygdala activation: Importance in the regulation of anxiety and pain behavior. Physiol Behav. 105: 371-375.

Traub RD, Whittington MA, Colling SB, Buzsáki G, Jefferys JG (1996). Analysis of gamma rhythms in the rat hippocampus in vitro and in vivo. $J$ Physiol 493: 471-484.

van der Kolk BA (1989). The compulsion to repeat the trauma: reenactment, revictimization, and masochism. Psyhiatr Clin North Am 12: 389-411.

Volman V, Behrens MM, Sejnowski TJ (2011). Downregulation of parvalbumin at cortical GABA synapses reduces network gamma oscillatory activity. J Neurosci 31: 18137-18148.

Supplementary Information accompanies the paper on the Neuropsychopharmacology website (http://www.nature.com/npp) 